\title{
Self-referrals in the emergency department: reasons why patients attend the emergency department without consulting a general practitioner first-a questionnaire study
}

Nicole Kraaijvanger ${ }^{1 *}$, Douwe Rijpsma ${ }^{1}$, Henk van Leeuwen ${ }^{2}$ and Michael Edwards ${ }^{3}$

\begin{abstract}
Background: To influence self-referral, it is crucial to know a patient's motives to directly visit the emergency department (ED). The goal of this study is to examine motives for self-referral to the ED and compare these motives in relation to appropriateness.

Methods: All self-referred patients visiting the ED of a Dutch hospital over four separate months in a 1-year period were included. Patients were handed questionnaires that included questions on their reasons to visit the ED directly and where they would seek medical help next time. Additionally, the motives of patients that either appropriately or inappropriately visited the ED were compared. In a previous study on the same patient cohort, the appropriateness of the ED visits was determined using predefined criteria.

Results: A total of 3196 self-referred patients were included, and $48.9 \%$ completed the questionnaires. The majority of patients $(28.0 \%)$ attended the ED without a referral because they thought they would get help faster; the next reason was the easier access to radiologic and laboratory investigations (answered by $23.8 \%$ ); and the third was the symptoms were considered too severe to visit a general practitioner (GP) (answered by $22.7 \%$ ). The majority (78.5\%) would attend the ED the next time they are faced with similar symptoms. Appropriate visits were significantly more seen in females, elderly, and patients in higher triage categories. Patients who expect investigations are necessary, think their symptoms are too severe to visit a GP, or would return to the ED next time were more often appropriately visiting the ED.

Conclusions: The choice of patients to self-refer to an ED is often an explicate decision. Patients are looking for specialist help and want fast and easy access to radiologic and laboratory investigations. Even though the primary care network is well developed in the Netherlands, the reasons for self-referral are similar to the reasons found in previous literature based in other countries. Patients who visit the ED because of health concerns visit the ED more often appropriately than patients visiting for practical reasons.
\end{abstract}

Keywords: Emergency department, Self-referrals, Motives, Appropriateness, Questionnaires

\footnotetext{
*Correspondence: n.kraaijvanger@hotmail.nl

'Emergency Department, Rijnstate Hospital, Wagnerlaan 55, Arnhem, The Netherlands

Full list of author information is available at the end of the article
} 


\section{Background}

The question of inappropriate self-referrals to the emergency department (ED) is contentious and continues to provoke discussion in the light of increasing healthcare expenses and crowding.

The healthcare system in the Netherlands has a strong primary care network. The general practitioner (GP) serves as a gatekeeper, referring patients with acute illnesses to the ED, only if deemed necessary. During working hours, patients can consult their own GP; in out-of-office hours, they can consult a GP at a GP cooperative. However, patients can also choose to go directly to the ED. A recent Dutch study found that self-referred visits account for an average of $30 \%$ of all ED visits [1]. Many of these patients present with problems that possibly could be taken care of by a GP at lower costs [2-4]. Consequently, to reduce costs, policymakers in healthcare and insurance companies are investigating methods to reduce the number of self-referrals to the ED.

In the Netherlands, people are obligated to have health insurance. In 2008, a deductible of $150 €$ was introduced. This deductible gradually increased over the years to 375 $€$ in 2015. When someone reaches their deductible amount, additional medical visits (including ED visits) are fully covered by medical insurance. This deductible does not apply to care provided by a GP. Despite these measures, the number of ED visits has not decreased over the past years and it is not clear whether the number of inappropriate visits has.

To influence self-referral, it is essential to know the patient's motives to directly visit the ED, bypassing their GP. Previous studies found multiple reasons for patients to self-refer to the ED, ranging from practical issues to concerns of having a serious condition [3, 5-13]. However, most of these previous studies did not include the entire ED population or were not conducted in the Netherlands. The goal of this study is to explore the motives of self-referred patients to directly visit the ED in the Netherlands and to compare the motives of patients either appropriately or inappropriately visiting the ED.

\section{Methods}

\section{Study design}

This is an observational and prospective study. Selfreferred patients in the ED were handed questionnaires with questions on their reasons to visit the ED. Next, predefined criteria (Table 1) were used to compare the motives of patients that either appropriately or inappropriately visited the ED.

\section{Study setting}

This study is performed in the ED of a 955-bed community teaching hospital in the Netherlands (Rijnstate
Table 1 Predefined criteria determining the appropriateness of the ED visit

\begin{tabular}{ll}
\hline Secondary care (appropriate) & Primary care (inappropriate) \\
\hline Laboratory investigations & Urine testing only \\
ECG & \\
Immediate radiologic investigations \\
(X-ray, CT, ultrasound, MRI) & \\
$\begin{array}{l}\text { Extensive wounds that needed } \\
\text { follow-up in a specialist office }\end{array}$ & $\begin{array}{l}\text { Simple suture wounds that did } \\
\text { not need follow-up or could } \\
\text { be followed up by a GP }\end{array}$ \\
$\begin{array}{l}\text { Complications/symptoms related } \\
\text { to previous hospital treatment } \\
\text { Indication for surgery }\end{array}$ \\
Hospital admission
\end{tabular}

Hospital) that covers an area with 460,000 inhabitants. The ED is $24 / 7$ staffed by a team consisting of nine emergency physicians and 27 emergency medicine residents. In 2012, there were 36,721 ED visits, of which 12,383 patients $(33.7 \%)$ were hospitalized. The nearest GP cooperative is $5.6 \mathrm{~km}$ (3.48 miles) away.

In 2012, 93 EDs were operational 24/7 in the Netherlands. Twenty-eight EDs were in hospitals of the association of tertiary medical teaching hospitals (STZ-hospitals), as is the Rijnstate Hospital. In this category, there was an average of 31,346 visits per ED in 2012 (ranging from 17,000 to 50,000 ED visits). The average percentage of hospitalized patients in STZhospitals was $32 \%$ (ranging from 8 to $43 \%$ ) [1].

\section{Participants}

After approval from the Local Ethics Committee of the Rijnstate Hospital, all self-referred patients visiting the ED were included. Patients attending the ED on their own initiative, without a referral from a GP and not brought in by ambulance were considered 'self-referred'. No exclusion criteria were used. To avoid bias based on seasonal variation, patients were included in four separate months (April, July and October of 2012, and January of 2013). This patient cohort was subject of a previous study, concerning the percentage of appropriate visits of self-referred patients in the ED [4].

\section{Questionnaires}

Questionnaires were handed to the participants. When the patient was under the age of 12, caregivers were asked to fill out the questionnaire. First, they could fill in what the reason (symptom) was to attend the ED. These reasons were then coded using the 'Reason for Visit Classification for Ambulatory Care', developed by the US Department of Health, Education, and Welfare in 1979 [14]. Second, patients could fill in why they visited the ED directly. This was a multiple choice question, but 
there was a possibility to give an open answer. When patients wrote a statement that was similar to one of the multiple choice answers, it was classified as such. When patients chose more than one answer to this question, all answers were included. Third, patients could fill in where they would go the next time, confronted with similar symptoms; this was a multiple choice question. Informed consent was obtained from the participants.

\section{Appropriate versus inappropriate visits}

The motive of self-referrals to directly visit the ED was the primary outcome of this study. In addition, the motives of patients that either appropriately or inappropriately visited the ED were compared. In a previous study, performed on the same patient cohort, the percentage of appropriate visits to the ED was determined using predefined criteria [4]. These criteria classified an ED visit as appropriate, when it warranted diagnostic testing or treatment that could only be performed in a hospital (Table 1). These criteria were applied after the primary assessment in the ED and were not known to the treating physician. The predefined criteria classified 1878 ED visits $(58.8 \%)$ as appropriate.

\section{Statistics}

All data were analyzed in SPSS Statistics (SPSS Inc. PASW Statistics for Windows, version 19.0). Descriptive statistics were used to describe the patient population. We explored whether the appropriateness of an ED visit was related to gender, age, Manchester triage category, reasons to visit the ED directly and where patients would seek medical help next time. Differences in distributions of these categorical variables were compared using the Pearson chi-square test. A $P$ value less than 0.05 was considered statistically significant. To control the false discovery rate in multiple testing (i.e. reduce the probability of type I errors), the Benjamini-Hochberg method was used.

\section{Results}

During the inclusion period, a total of 12,409 patients attended the ED. Twenty-six percent (3196 patients) visited the ED without a referral from a GP (of which $9.4 \%$ were hospitalized). A total of 1563 patients completed the questionnaire, which results in a response rate of $48.9 \%$. Of these patients, $6.2 \%$ was hospitalized. Table 2 shows the patient characteristics and the percentages of different patient categories either appropriately or inappropriately visiting the ED. Appropriate visits were significantly more seen in female patients, elderly and higher triage categories.
Fifteen hundred thirty-seven patients $(48.1 \%)$ filled out their reason (symptom) to visit the ED. Using the Reason for Visit Classification, 201 different reasons were registered. The most common reasons for visiting the ED were injuries and musculoskeletal symptoms, followed by malaise symptoms and abdominal complaints (Table 3).

Fifteen hundred sixty one patients $(48.8 \%)$ answered the question why they attended the ED without a referral. Table 4 shows the distribution of the given answers. The three most chosen reasons were the following: the expectation to get help faster going directly to the ED (437 patients, $28.0 \%$ ), the expectation to need radiologic or laboratory investigations (372 patients, $23.8 \%$ ), and the presumption that the symptoms were too severe to visit a GP (355 patients, $22.7 \%$ ). When focusing on appropriateness in relation to these answers, it is notable that patients expecting investigations to be necessary or thinking their symptoms are too severe to visit a GP significantly more often appropriately visited the ED. Patients that were from a different region were significantly less often classified as appropriately visiting the ED.

Patients could also choose to give an open answer to this question; this was done by 191 patients. Different answers, that were not a multiple choice option, were given: 'The concierge send me to the hospital', 'I want more specific help, like stitches, injections etc., 'My GP will send me to the ED anyway', and 'I did not want to take any risk'.

Fourteen hundred six patients $(44.0 \%)$ answered the question where they would go the next time they are suffering from similar symptoms. The majority, 1104 patients (78.5 \%), answered they would again turn primarily to the ED, 320 patients $(22.8 \%)$ would visit a GP or a GP cooperative next time, and 16 patients $(1.1 \%)$ would seek no medical help at all. Some patients selected multiple answers to this question. When appropriateness was taken into account in relation to these answers, it was found that patients returning to the ED were significantly more often appropriately visiting the ED, whereas patients that would turn to their GP or seek no medical help were significantly more often inappropriately visiting the ED (Table 5).

The Benjamini-Hochberg method was applied on the tests shown in Tables 2, 4, and 5. After this correction, the $P$ value 0.049 is no longer significant (Table 4: GP could/would not see me).

\section{Discussion}

The present study used questionnaires to explore motives of self-referred patients visiting the ED. It is remarkable to see that the reasons for self-referral are similar even in the Netherlands, which has a well-developed primary care system. 
Table 2 Patient characteristics versus appropriateness

\begin{tabular}{|c|c|c|c|c|c|c|}
\hline Category & Variable & Total N (\%) & Quest. N (\%) & Appropr. N (\%) & Inapp. N (\%) & $P$ value \\
\hline \multirow[t]{2}{*}{ Gender } & Male & $1875(59)$ & $932(50)$ & $519(56)$ & $413(44)$ & 0.019 \\
\hline & Female & $1321(41)$ & $631(48)$ & $389(62)$ & $242(38)$ & \\
\hline \multirow[t]{5}{*}{ Age } & $<18$ & $697(22)$ & $337(48)$ & $177(53)$ & $160(48)$ & $<0.001$ \\
\hline & $18-39$ & $1308(41)$ & $646(49)$ & $347(54)$ & $299(46)$ & \\
\hline & $40-59$ & $778(24)$ & $386(50)$ & $253(66)$ & $133(35)$ & \\
\hline & $60-79$ & $346(11)$ & $162(47)$ & $106(65)$ & $56(35)$ & \\
\hline & $>80$ & $67(2)$ & $32(48)$ & $25(78)$ & $7(22)$ & \\
\hline \multirow[t]{6}{*}{ Manchester Triage category } & Red & $1(0.03)$ & $0(0)$ & $0(0)$ & $0(0)$ & $<0.001$ \\
\hline & Orange & $178(6)$ & $57(32)$ & $51(89)$ & $6(11)$ & \\
\hline & Yellow & $1189(37)$ & $550(46)$ & $378(69)$ & $172(31)$ & \\
\hline & Green & $1788(56)$ & $944(53)$ & $477(51)$ & $467(49)$ & \\
\hline & Blue & $30(1)$ & $12(40)$ & $2(17)$ & $10(83)$ & \\
\hline & No triage & $10(0.3)$ & $0(0)$ & $0(0)$ & $0(0)$ & \\
\hline
\end{tabular}

Total $N(\%)$ number of self-referred patients per group (percentage of category), Quest. $N$ (\%) number of questionnaires filled out per group (percentage), Appropr. $N(\%)$ number of appropriate visits by patients that filled out the questionnaires per group (percentage of appropriate visits per group), Inapp. $N$ (\%) number of inappropriate visits by patients that filled out the questionnaires per group (percentage of inappropriate visits per group), $P$ value appropriate versus inappropriate, per category

This study found that the main reason for most patients to skip a visit to their GP and go straight to the ED is the expectation that they would get medical help sooner. Several patients answered that it is devious to visit a GP or GP cooperative first, to be referred to an $\mathrm{ED}$ 'anyway'. This is mostly true in a situation where the GP cooperative and ED are not closely situated, like it is the case in the hospital this study was conducted in. Previous research also found that time is playing a major role in choosing to attend an ED [3, 9, 15]. Many selfreferrals responded that their symptoms were too severe to visit a GP. This is consistent with earlier studies showing that health concerns and the belief of having an urgent medical problem play a major role in deciding to attend an ED [7-13, 16]. Furthermore, this study, in concordance with previous research, found that patients often are convinced that they need radiologic or laboratory investigations to get a diagnosis $[3,6,16]$. It therefore seems a logical step to attend to the ED directly, where it is possible to get these investigations. Consistent with previous literature, this study found that patients are frequently supported in their decision to visit an ED by family members or paramedics $[6,11]$. The majority of the self-referred patients visited with injuries and other symptoms of the musculoskeletal system. Our results are again consistent with previous studies, showing that injuries and musculoskeletal symptoms are frequent reasons to attend an $\operatorname{ED}[3,6,11,17]$.

Multiple non-Dutch studies found that the unavailability of a GP is a major reason to self-refer to an ED, especially after hours $[7,8,15,16]$. The present study found that this was a reason to attend the ED for almost

Table 3 Ten most common reasons for visit, classified into categories using The Reason for Visit Classification

\begin{tabular}{llcc}
\hline Code & Reason for visit category & Number & Percentage \\
\hline J505-J575 & Injury, type unspecifiedfor example 'foot bumped', 'hurt my hand' & 356 & 23.2 \\
J205-J230 & Injury, lacerations, and cutsfor example 'cut in finger' & 253 & 16.5 \\
S900-S999 & $\begin{array}{l}\text { Symptoms referable to the musculoskeletal system, excluding injuriesfor example 'low } \\
\text { back pain', 'stiffness knee' }\end{array}$ & 195 & 132 \\
J800-J899 & Injury, not otherwise specifiedfor example 'motor vehicle accident', 'fell from stair cases' & 113 & 9.7 \\
S001-S099 & General symptomsfor example 'malaise', 'fainting' & 98 & 7.4 \\
S500-S639 & Symptoms referable to the digestive systemfor example 'abdominal pain', 'nausea' & 6.4 \\
J001-J050 & Injury, fractures, and dislocationsfor example 'fracture wrist', 'dislocated shoulder' & 49 \\
J105-J130 & Injury, sprains, and strainsfor example 'sprained ankle', 'twisted knee' & 40 \\
S400-S499 & Symptoms referable to the respiratory systemfor example 'shortness of breath', 'pain throat' & 3.8 \\
S300-S399 & Symptoms referable to the eyes and earsfor example 'red eye', 'pain ear' & 3.2 \\
\hline
\end{tabular}


Table 4 Answers to the question why self-referred patients directly attended the ED

\begin{tabular}{|c|c|c|c|c|}
\hline Multiple choice answer & Number (\%) & Appropriate (\%) & Inappropriate (\%) & $P$ value \\
\hline Patients that answered this question & 1561 & $908(58.2)$ & $653(41.8)$ & \\
\hline Takes less time & $437(28.0)$ & $250(27.5)$ & $187(28.6)$ & 0.632 \\
\hline Investigations necessary & $372(23.8)$ & $246(27.1)$ & $126(19.3)$ & $<0.001$ \\
\hline Symptoms too severe & $355(22.7)$ & $227(25.0)$ & $128(19.6)$ & 0.012 \\
\hline Not from the region & $258(16.5)$ & $131(14.4)$ & $127(19.4)$ & 0.008 \\
\hline GP not available & $145(9.3)$ & $83(9.1)$ & $62(9.5)$ & 0.812 \\
\hline GP could/would not see me & $130(8.3)$ & $65(7.2)$ & $65(10.0)$ & $0.049^{*}$ \\
\hline No confidence in GP & $47(3.0)$ & $30(3.3)$ & $17(2.6)$ & 0.424 \\
\hline No GP & $20(1.3)$ & $8(0.9)$ & $12(1.8)$ & 0.097 \\
\hline
\end{tabular}

Patients could choose more than one answer

Number (\%) number of patients that chose this answer (percentage), Appropriate (\%) number of patients that chose this answer, whose visit was considered appropriate (percentage of patients with an appropriate visit that chose this answer), Inappropriate (\%) number of patients that chose this answer, whose visit was considered inappropriate (percentage of patients with an inappropriate visit that chose this answer)

The data in italics represent signifant $P$-values *After applying the Benjamini-Hochberg method, this $P$ value is no longer significant

a fifth of the self-referrals. This result, however, is in contrast with previous Dutch studies on this subject, stating that problems in consulting a GP were not often a reason to self-refer $[3,18]$. This discrepancy is interesting. In the Netherlands, the primary healthcare system is well organized: patients can visit their own GP in daytime and, with the continuing development of GP cooperatives since the mid-1990s, they have a perceived easy access to primary care in the evening and night as well. The present study shows that Dutch patients nonetheless are having difficulties in gaining an appointment with a GP in a timely manner. This might be caused by increasingly busy general practices and enlarging GP cooperatives taking care of growing numbers of patients, leading to more bureaucracy and stricter regulations for getting an appointment. In addition, the modern patient seems to expect and demand medical care at the moment he/she thinks this is mandatory, and is increasingly less willing to wait for an appointment.

When concentrating on the appropriateness in relation to the answers patients selected, it seems that patients do have a sense of when to visit the ED for their symptoms. Patients visiting the ED because of health concerns are more often visiting the ED appropriately than patients visiting out of practical reasons. To the best of our knowledge, there are no previous studies looking at the motives of self-referred patients for visiting the ED in relation to the appropriateness of their visits.

\section{Limitations}

This study made use of a questionnaire that was not validated. However, to the best of our knowledge, there is no validated questionnaire regarding this subject. The response rate to the questionnaire was $48.9 \%$, which is relatively low. This makes it possible that the included answers are not a reflection of the opinion of all self-referred patients.

This study made use of predefined criteria to determine whether an ED visit was appropriate. This method can lead to an overestimation of the number of appropriate visits because it is possible that physicians working in the ED order more investigations than a GP would with the same patient. In our previous study, we also used diagnoses and treatments given to the included patients to determine appropriateness [4]. With this method, $48.1 \%$ of the self-referrals was found appropriate versus $58.8 \%$ using the predefined criteria. In order to make the current study not too complicated, the choice was made to include only the predefined criteria.

Another limitation of this study is the possibility of interobserver bias. Different physicians working in the ED may order different investigations with similar symptoms, which can lead to different outcomes using the predefined criteria. These individual variations are not completely avoidable, and the effect on the percentage of appropriateness is not clear. This study was performed in a single ED. This limits the possibility to extrapolate the results to other EDs in the Netherlands or other countries.

Table 5 Answers to the question where self-referred patients would seek medical help, confronted with similar symptoms

\begin{tabular}{lllll}
\hline Multiple choice answer & Number (\%) & Appropriate (\%) & Inappropriate (\%) & $P$ value \\
\hline ED & $1104(78.5)$ & $686(62.1)$ & $418(37.9)$ & $<0.001$ \\
GP & $320(22.8)$ & $144(45.0)$ & $176(55.0)$ & $<0.001$ \\
No medical help & $16(1.1)$ & $5(31.3)$ & $11(68.8)$ & 0.029 \\
\hline
\end{tabular}




\section{Conclusions}

This study, carried out in a community hospital in the Netherlands, found that the choice of patients to selfrefer to an ED is often a considered decision. Patients are looking for specialist help for their perceived urgent symptoms and want fast and easy access to radiologic and laboratory investigations. While the Netherlands has a well-developed primary care network, the reasons for self-referral in the Netherlands are similar to reasons found in previous literature based in other countries. Despite the strong primary care, Dutch patients report difficulties in gaining a timely appointment with a GP. Patients visiting the ED out of health concerns are more often visiting appropriately versus patients visiting for more practical reasons.

\section{Competing interests}

The authors declare that they have no competing interests.

\section{Authors' contributions}

NK and DR designed the study and the questionnaires. NK collected the data and performed the statistical analysis (with help of Lian Roovers). $\mathrm{DR}, \mathrm{HL}$ and ME revised the article and approved the final manuscript. All authors revised the article and approved the final manuscript.

\section{Acknowledgements}

The authors thank Lian Roovers, who helped with the statistics, and the emergency physicians, residents, and nurses that helped including the patients.

\section{Author details}

${ }^{1}$ Emergency Department, Rijnstate Hospital, Wagnerlaan 55, Arnhem, The Netherlands. ${ }^{2}$ Department of Internal Medicine/Intensive Care, Rijnstate Hospital, Wagnerlaan 55, Arnhem, The Netherlands. ${ }^{3}$ Trauma Surgery/ Emergency Department, Radboud University Medical Centre, Geert Grooteplein Zuid 10, Nijmegen, The Netherlands.

Received: 18 July 2015 Accepted: 2 November 2015

Published online: 07 December 2015

\section{References}

1. Gaakeer M, van den Brand C, Veugelers R, Patka P. Inventarisatie van SEH-bezoeken en zelfverwijzers [Inventory of attendance at Dutch emergency departments and self-referrals]. Ned Tijdschr Geneeskd. 2014;158:A7128.

2. Giesbers S, Smits M, Giesen P. Zelfverwijzers SEH jagen zorgkosten op [Self-referrals in the ED raise healthcare costs]. Medisch Contact. 2011;10:587-90.

3. Jaarsma-van LI, Hammacher E, Hirsch R, Janssens M. Patienten zonder verwijzing op de afdeling Spoedeisende Hulp: patientkarakteristieken en motieven. [Patients without referral treated in the emergency room: patient characteristics and motives]. Ned Tijdschr Geneeskd. 2000;144:9.

4. Kraaijvanger N, Rijpsma D, van Leeuwen H, van Dijk N, Edwards M. Self-referrals in a Dutch emergency department: how appropriate are they? Eur J Emerg Med. 2014; doi: 10.1097/MEJ.0000000000000216

5. Ragin DF, Hwang U, Cydulka RK, Holson D, Haley Jr LL, Richards CF, et al. Reasons for using the emergency department: results of the EMPATH study. Acad Emerg Med. 2005;12:12.

6. van Charante EP M, ter Riet G, Bindels P. Self-referrals to the A\&E department during out-of-hours: patients' motives and characteristics. Patient Educ Couns. 2008;70:2.

7. Agarwal S, Banerjee J, Baker R, Conroy S, Hsu A, Rashid J. Potentially avoidable emergency department attendance: interview study of patient' reasons for attendance. Emerg Med J. 2011; doi:10.1136/emermed-2011-200585

8. Doobinin KA, Heidt-Davis PE, Gross TK, Isaacman DJ. Nonurgent pediatric emergency department visits: care-seeking behavior and parental knowledge of insurance. Ped Emerg Care. 2003;19:1.
9. Hendry SJ, Beattie TF, Heaney D. Minor illness and injury: factors influencing attendance at a paediatric accident and emergency department. Arch Dis Child. 2005;90:6.

10. Northington WE, Brice JH, Zou B. Use of emergency department by nonurgent patients. Am J Emerg Med. 2005;23:2.

11. Rassin M, Nasie A, Bechor $Y$, Weiss G, Silner D. The characteristics of self-referrals to ER for non-urgent conditions and comparison of urgency evaluation between patients and nurses. Accid Emerg Nurs. 2006;14:1.

12. Weiss AL, D'Angelo $L$, Rucker AC. Adolescent use of the emergency department instead of primary care provider: who, why, and how urgent? J Adolesc Health. 2014;54:4.

13. van der Linden MC, Lindeboom R, van der Linden $N$, van den Brand C, Lam RC, Lucas $C$ et al. Self-referring patients at the emergency department: appropriateness of ED use and motives for self-referral. Internat J Emerg Med. 2014; doi: 10.1186/s12245-014-0028-1

14. U.S. Department of Health, Education, and Welfare, A reason for visit classification for ambulatory care, DHEW Publication No. (PHS) 1979, 2:78.

15. Howard MS, Davis BA, Anderson C, Cherry D, Koller P, Shelton D. Patients' perspective on choosing the emergency department for nonurgent medical care: a qualitative study exploring one reason for overcrowding. J Emerg Nurs. 2005;31:5.

16. Field S, Lantz A. Emergency department use by CTAS Levels IV and $\checkmark$ patients. Can J Emerg Med. 2006;8:5.

17. Giesen P, Franssen E, Mokkink H, van den Bosch W, van Vught A, Grol R. Patients either contacting a general practice cooperative or accident and emergency department out of hours: a comparison. Emerg Med J. 2006;23:9.

18. Rieffe C, Oosterveld P, Wijkel D, Wiefferink C. Reasons why patients bypass their GP to visit a hospital emergency department. Accid Emerg Nurs. 1999;7:4.

\section{Submit your manuscript to a SpringerOpen ${ }^{\circ}$ journal and benefit from:}

- Convenient online submission

Rigorous peer review

- Immediate publication on acceptance

- Open access: articles freely available online

- High visibility within the field

- Retaining the copyright to your article

Submit your next manuscript at springeropen.com 